Article

\title{
The Regulation of Anthocyanin Synthesis in the Wheat Pericarp
}

\section{Olesya Y. Shoeva ${ }^{1, *}$, Elena I. Gordeeva ${ }^{1}$ and Elena K. Khlestkina ${ }^{1,2}$}

1 Institute of Cytology and Genetics, Siberian Branch, Russian Academy of Sciences, Lavrentjeva ave. 10, Novosibirsk 630090, Russia; E-Mails: elgordeeva@bionet.nsc.ru (E.I.G.); khlest@bionet.nsc.ru (E.K.K.)

2 Novosibirsk State University, Pirogova St. 2, Novosibirsk 630090, Russia

* Author to whom correspondence should be addressed; E-Mail: olesya_ter@bionet.nsc.ru; Tel.: +7-383-363-4952; Fax: +7-383-333-1278.

External Editor: Ronald E. Wrolstad

Received: 30 September 2014; in revised form: 24 November 2014 / Accepted: 27 November 2014 / Published: 4 December 2014

\begin{abstract}
Bread wheat producing grain in which the pericarp is purple is considered to be a useful source of dietary anthocyanins. The trait is under the control of the $P p-1$ homoealleles (mapping to each of the group 7 chromosomes) and Pp3 (on chromosome 2A). Here, $T a M y c 1$ was identified as a likely candidate for $P p 3$. The gene encodes a MYC-like transcription factor. In genotypes carrying the dominant $P p 3$ allele, TaMycl was strongly transcribed in the pericarp and, although at a lower level, also in the coleoptile, culm and leaf. The gene was located to chromosome $2 \mathrm{~A}$. Three further copies were identified, one mapping to the same chromosome arm as TaMycl and the other two mapping to the two other group 2 chromosomes; however none of these extra copies were transcribed in the pericarp. Analysis of the effect of the presence of combinations of $P p 3$ and $P p-1$ genotype on the transcription behavior of TaMycl showed that the dominant allele $P p-D 1$ suppressed the transcription of TaMycl.
\end{abstract}

Keywords: Triticum aestivum; purple grain pericarp; candidate gene; regulatory gene; nucleotide sequence; transcription 


\section{Introduction}

The anthocyanins represent a class of secondary metabolites synthesized by most higher plants. They are responsible for the pigmentation of flowers and fruits, and function as attractors for the vectors of pollen and seeds. Their presence in vegetative tissue is associated with the response to biotic and abiotic stress $[1,2]$, enabled by their ability to neutralize free radicals, chelate heavy metal ions, and aid in osmoregulation and photoprotection [1-7]. In addition, their inclusion in the human diet is beneficial in numerous ways [8-13]. The main source of dietary anthocyanins is berries and fruits, but in recent years, cereals are also being considered as additional sources of these compounds [14-19].

In bread wheat (Triticum aestivum L., $2 n=6 x=42$, BBAADD) grain the anthocyanins reside either in the pericarp or in aleurone layer; the grain of some accessions has a purple or blue appearance as a result of the anthocyanin content of one or other of these tissues [20]. The genetic basis of purple grain pigmentation resides in the action of the homoeallelic $P p-1$ genes and $P p 3$ [21-25]. The former map to the short arms of the homeologous group 7 chromosomes [21-25], and the latter to chromosome arm 2AL [21-23]. Comparative mapping has shown that the $P p-1$ genes are orthologs of both maize $C 1$ and rice $O s C 1$, which encode MYB-like transcription factors (TFs) responsible for the activation of structural genes encoding various enzymes participating in anthocyanin synthesis [26-28] (Supplementary Table S1). Similarly, $P p 3$ has been shown to be orthologous to both $P b / R a$ in rice [29,30] and $L c / R$ in maize [31], which encode MYC-like TFs underlying the regulation of anthocyanin synthesis (Supplementary Table S1). Regulatory role of the $P p$ genes has been confirmed by functional analysis of the anthocyanin synthesis structural genes in wheat near-isogenic lines (NILs) differing by the allelic state of the $P p-1$ and $P p 3$ genes (both genes were in dominant or recessive state) [32]. Here, the nucleotide sequence of $P p 3$ has been determined, and a functional characterization of the gene has been described.

\section{Results}

\subsection{Identification and Chromosome Location of Wheat Myc-Like Sequences}

The BLAST search based on the maize $L c$ and rice $R a$ sequences identified a matching sequence on T. urartu BAC clone 404H6 (GenBank accession number EF081030, Supplementary Figure S1), and this sequence allowed the design of a wheat primer pair targeting the $M y c$-like sequences (Supplementary Table S2, Figures S1 and S2). When gDNA from the NIL "i:S29Pp-A1Pp-D1Pp3" (Table 1) was amplified using this primer pair, four distinct sequences were generated (Supplementary Figure S3). The pair-wise level of homology between the four sequences varied from $86.7 \%$ to $95.8 \%$ (Supplementary Table S3 and Figure S3). Three distinct sequences were amplified from $T$. durum gDNA in the same way. The eight sequences (four from T. aestivum, three from T. durum and one from T. urartu) formed three clusters: one grouped TaMyc1 and TdMyc1, the second TaMyc2, TdMyc2 and the T. urartu sequence, and the third TaMyc3,TdMyc3 and TaMyc4 (Figure 1). The sequence information was used to design a series of copy-specific primer pairs (Supplementary Table S2), which when applied to the aneuploid stocks of cv. "Chinese Spring", allowed TaMyc1 and TaMyc2 to be assigned to chromosome arm 2AL, TaMyc3 to chromosome arm 2BL and TaMyc4 to chromosome arm 2DL (Figure 2, Supplementary Figure S4). 
Table 1. Genetic stocks used to characterize the transcription of the $M y c$-like genes in the wheat grain pericarp (controlled by $P p 3$ and $P p-1$ ), the leaf $(P l b)$, the culm $(P c)$ and the coleoptile $(R c)$. D: dominant allele, R: recessive allele, NIL: near-isogenic line, *, **: genotypes, in which the pericarp is, respectively, dark and light purple.

\begin{tabular}{|c|c|c|c|c|c|c|c|c|c|c|c|c|c|c|c|}
\hline \multirow{2}{*}{ Name } & \multirow{2}{*}{ Alternative Name } & \multirow{2}{*}{ Description } & \multicolumn{3}{|c|}{$P p$} & \multicolumn{3}{|c|}{$P l b$} & \multicolumn{3}{|c|}{$P c$} & \multicolumn{3}{|c|}{$R c$} & \multirow{2}{*}{ References } \\
\hline & & & $-A 1$ & $-B 1$ & $-D 1$ & $-A 1$ & $-B 1$ & $-D 1$ & $-A 1$ & $-B 1$ & $-D 1$ & $-A 1$ & $-B 1$ & $-D 1$ & \\
\hline - i:S29Pp-A1pp-D1pp3 & $\begin{array}{c}\text { "Saratovskaya 29" } \\
\text { ("S29") }\end{array}$ & Russian spring wheat & $\mathrm{D}$ & $\mathrm{R}$ & $\mathrm{R}$ & $\mathrm{D}$ & $\mathrm{R}$ & $\mathrm{R}$ & $\mathrm{D}$ & $\mathrm{R}$ & $\mathrm{R}$ & $\mathrm{D}$ & $\mathrm{R}$ & $\mathrm{R}$ & {$[25,33]$} \\
\hline i:S29Pp-A1Pp-D1Pp3 $3^{\mathrm{PF} *}$ & $\mathrm{i}: \mathrm{S} 29 P p 1 P p 2^{\mathrm{PF}}$ & $\begin{array}{l}\text { wheat NIL developed on } \\
\text { "S29", donor - "Purple Feed" }\end{array}$ & $\mathrm{D}$ & $\mathrm{R}$ & $\mathrm{D}$ & $\mathrm{D}$ & $\mathrm{R}$ & $\mathrm{D}$ & $\mathrm{D}$ & $\mathrm{R}$ & $\mathrm{D}$ & $\mathrm{D}$ & $\mathrm{R}$ & $\mathrm{D}$ & {$[21,24,25]$} \\
\hline i:S29Pp-A1Pp-D1Pp3 $3^{\mathrm{P} *}$ & i:S29Pp $1 P p 3^{\mathrm{P}}$ & $\begin{array}{c}\text { wheat NIL developed on "S29", } \\
\text { donor-"Purple" }\end{array}$ & $\mathrm{D}$ & $\mathrm{R}$ & $\mathrm{D}$ & $\mathrm{D}$ & $\mathrm{R}$ & $\mathrm{D}$ & $\mathrm{D}$ & $\mathrm{R}$ & $\mathrm{D}$ & $\mathrm{D}$ & $\mathrm{R}$ & $\mathrm{D}$ & {$[21,24,25]$} \\
\hline - $\mathrm{i}: \mathrm{S} 29 P p-A 1 p p-D 1 P p 3^{\mathrm{PF} * *}$ & no & $\begin{array}{c}\text { wheat NIL developed on "S29", } \\
\text { donor-"Purple Feed" }\end{array}$ & $\mathrm{D}$ & $\mathrm{R}$ & $\mathrm{R}$ & $\mathrm{D}$ & $\mathrm{R}$ & $\mathrm{R}$ & $\mathrm{D}$ & $\mathrm{R}$ & $\mathrm{R}$ & $\mathrm{D}$ & $\mathrm{R}$ & $\mathrm{R}$ & {$[25]$} \\
\hline i:S29Pp-A1Pp-D1pp $3^{\mathrm{PF}}$ & no & $\begin{array}{c}\text { wheat NIL developed on "S29", } \\
\text { donor-"Purple Feed" }\end{array}$ & $\mathrm{D}$ & $\mathrm{R}$ & $\mathrm{D}$ & $\mathrm{D}$ & $\mathrm{R}$ & $\mathrm{D}$ & $\mathrm{D}$ & $\mathrm{R}$ & $\mathrm{D}$ & $\mathrm{D}$ & $\mathrm{R}$ & $\mathrm{D}$ & {$[25]$} \\
\hline i:S29Pp-A1pp-D1Pp $3^{\mathrm{P} * *}$ & no & $\begin{array}{c}\text { wheat NIL developed on "S29", } \\
\text { donor-"Purple" }\end{array}$ & $\mathrm{D}$ & $\mathrm{R}$ & $\mathrm{R}$ & $\mathrm{D}$ & $\mathrm{R}$ & $\mathrm{R}$ & $\mathrm{D}$ & $\mathrm{R}$ & $\mathrm{R}$ & $\mathrm{D}$ & $\mathrm{R}$ & $\mathrm{R}$ & {$[25]$} \\
\hline i:S29Pp-A1Pp-D1pp $3^{\mathrm{P}}$ & no & $\begin{array}{c}\text { wheat NIL developed on "S29", } \\
\text { donor-"Purple" }\end{array}$ & $\mathrm{D}$ & $\mathrm{R}$ & $\mathrm{D}$ & $\mathrm{D}$ & $\mathrm{R}$ & $\mathrm{D}$ & $\mathrm{D}$ & $\mathrm{R}$ & $\mathrm{D}$ & $\mathrm{D}$ & $\mathrm{R}$ & $\mathrm{D}$ & {$[25]$} \\
\hline $4 \mathrm{i}: \mathrm{S} 29 p p-A 1 p p-D 1 p p 3$ & $\begin{array}{c}\text { line 140; } \\
\text { "S29" ("YP" 4D*7A) }\end{array}$ & $\begin{array}{c}\text { wheat NIL developed on "S29", } \\
\text { donor-"Yanetzkis Probat" }\end{array}$ & $\mathrm{R}$ & $\mathrm{R}$ & $\mathrm{R}$ & $\mathrm{R}$ & $\mathrm{R}$ & $\mathrm{R}$ & $\mathrm{R}$ & $\mathrm{R}$ & $\mathrm{R}$ & $\mathrm{R}$ & $\mathrm{R}$ & $\mathrm{R}$ & {$[25,33]$} \\
\hline “Novosibirskaya 67” (“N67”) & no & Russian spring wheat & $\mathrm{R}$ & $\mathrm{R}$ & $\mathrm{D}$ & $\mathrm{R}$ & $\mathrm{R}$ & $\mathrm{D}$ & $\mathrm{R}$ & $\mathrm{R}$ & $\mathrm{D}$ & $\mathrm{R}$ & $\mathrm{R}$ & $\mathrm{D}$ & {$[24,34]$} \\
\hline "Purple"* & no & Australian spring wheat " $\mathrm{k}-46990$ " & $\mathrm{R}$ & $\mathrm{R}$ & $\mathrm{D}$ & $\mathrm{R}$ & $\mathrm{R}$ & $\mathrm{D}$ & $\mathrm{R}$ & $\mathrm{R}$ & $\mathrm{D}$ & $\mathrm{R}$ & $\mathrm{R}$ & $\mathrm{D}$ & {$[24]$} \\
\hline "Purple Feed"* & no & Canadian spring wheat " $\mathrm{k}-49426$ " & $\mathrm{R}$ & $\mathrm{R}$ & $\mathrm{D}$ & $\mathrm{R}$ & $\mathrm{R}$ & $\mathrm{D}$ & $\mathrm{R}$ & $\mathrm{R}$ & $\mathrm{D}$ & $\mathrm{R}$ & $\mathrm{R}$ & $\mathrm{D}$ & {$[24]$} \\
\hline
\end{tabular}

names for NILs obtained on "Saratovskaya 29" with dominant alleles $P p-D 1$ and/or Pp3 inherited from cultivars "Purple" (P) or "Purple Feed" (PF); in these lines dominant allele of $P p-A 1$ is from "Saratovskaya 29"; name for NIL obtained on "Saratovskaya 29" with its own recessive alleles $p p-D 1$ and $p p 3$ and recessive $p p-A 1$ inherited from "Yanetzkis Probat". 
Figure 1. Myc-like sequence phylogeny. The sequences shown underlined were isolated in the current study, while the remainders were downloaded from GenBank.
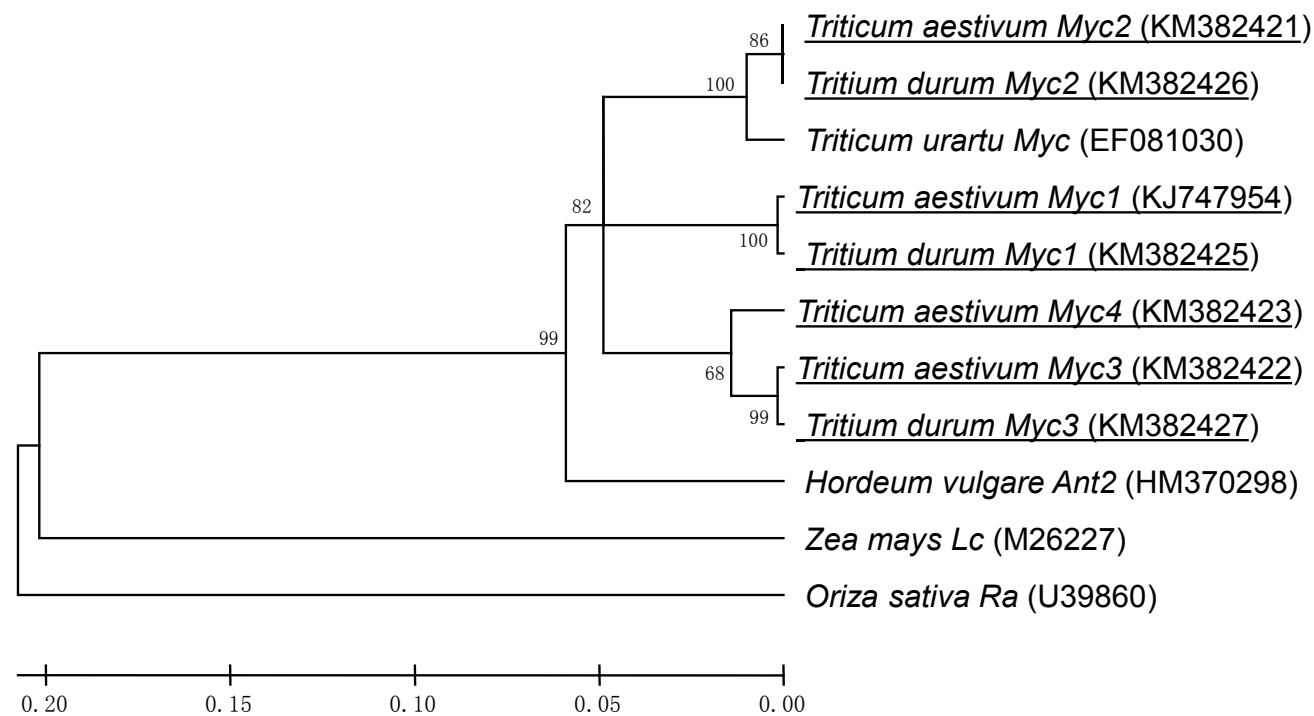

Figure 2. Chromosome location of wheat $M y c$ genes.
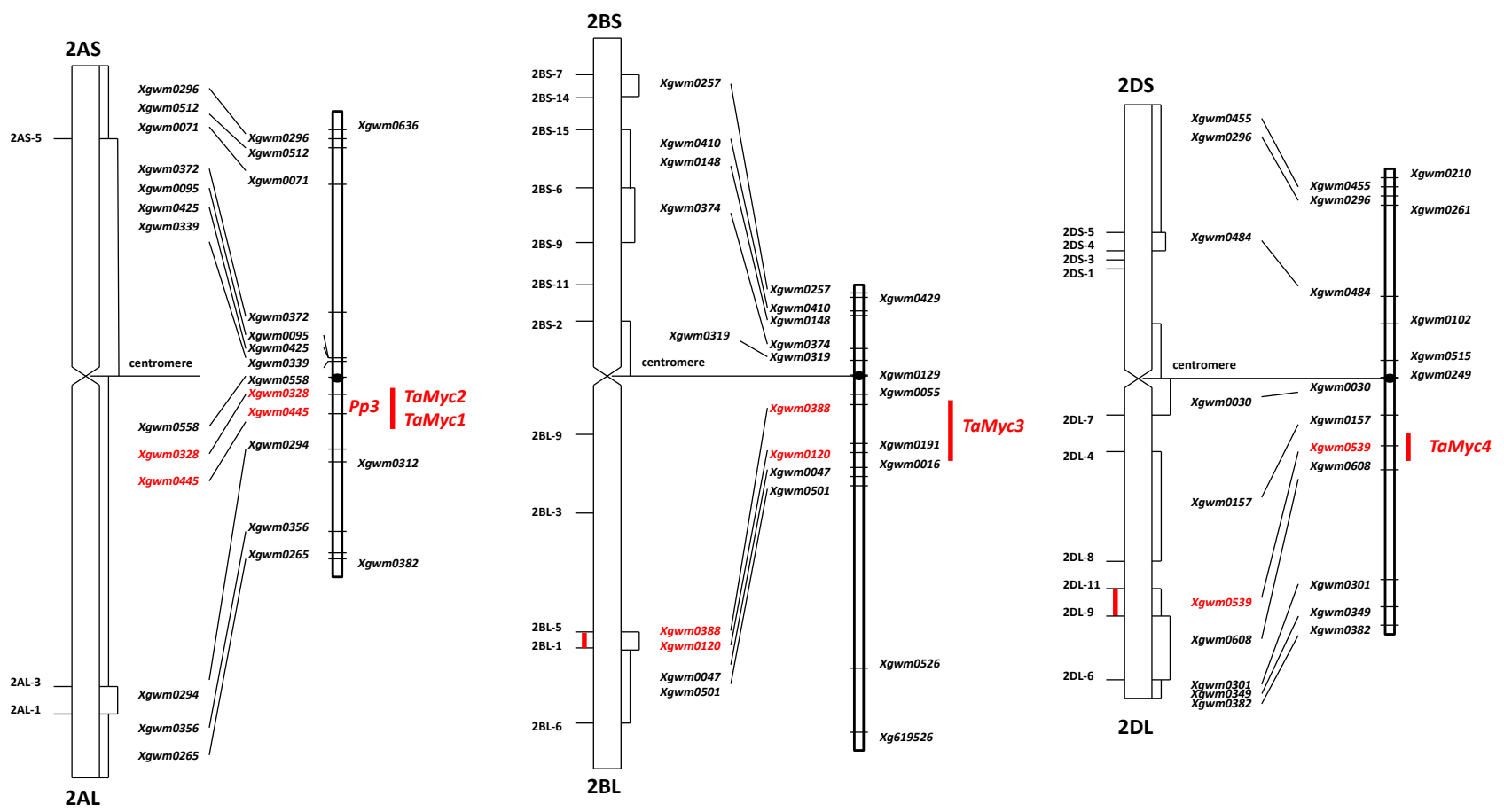

\subsection{Functional Activity of the Wheat Myc Gene Copies}

The transcript abundance of each $M y c$ gene in the grain pericarp was derived by RT-PCR. Only TaMycl was strongly represented in the pericarp transcriptome of genotypes harboring dominant alleles at $P p-1$ and $P p 3$. The transcription profile of TaMycl was similar to that of the anthocyanin synthesis pathway genes encoding for flavanone 3-hydroxylase (F3H), dihydroflavonol-4-reductase (DFR) and anthocyanidin synthase (ANS) (Figure 3). 
Figure 3. Transcription of the $M y c$ gene copies in the pericarp of cv. "Novosibirskaya 67" (1); cv. "Saratovskaya 29" (2-4); "i:S29Pp-A1Pp-D1Pp3 $3^{\mathrm{P} "}$ NIL (5-6); "i:S29Pp-A1Pp-D1Pp3 ${ }^{\mathrm{PF},}$ NIL (7,8); cv. "Purple" (9) and cv. "Purple Feed" (10).

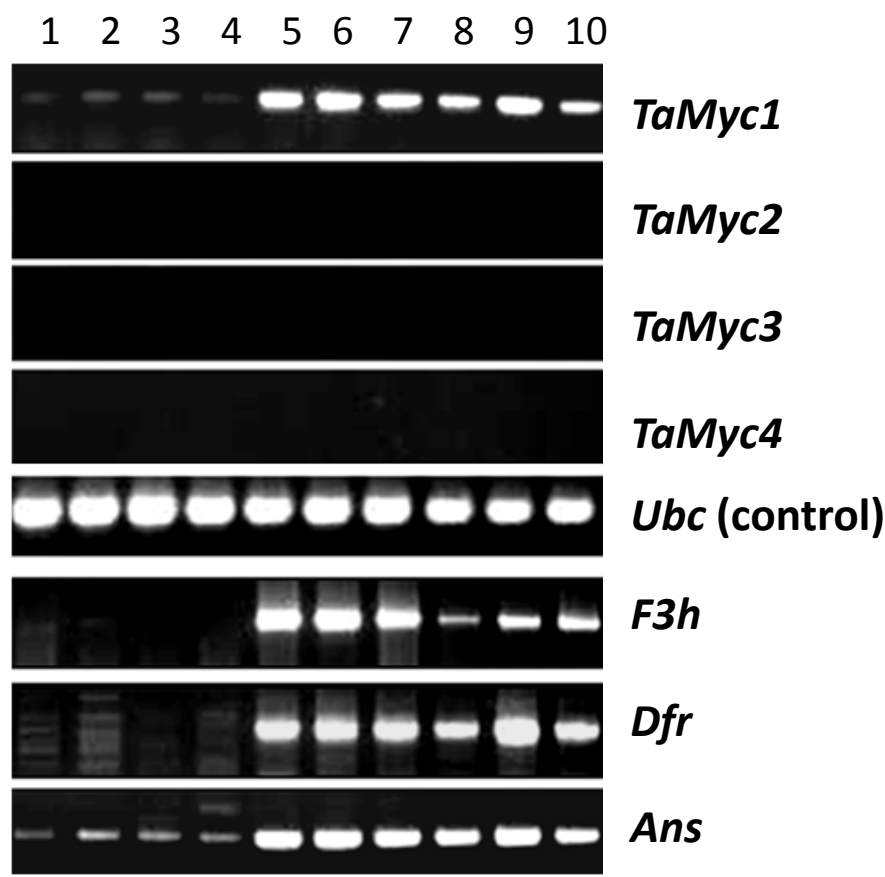

The quantitative RT-PCR analysis showed that TaMycl transcript was more abundant in both NILs

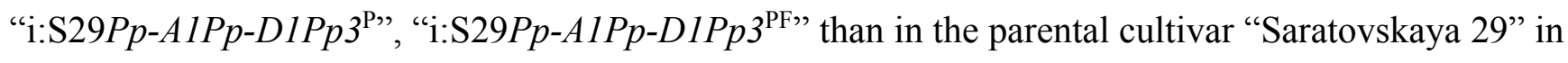
all tissues investigated, while the level present in the pericarp was two-three orders of magnitude higher than elsewhere in the plant (Figure 4).

Figure 4. Transcription of TaMycl in various parts of the wheat plant. Statistical analysis of transcript abundances given in Supplementary Table S4.

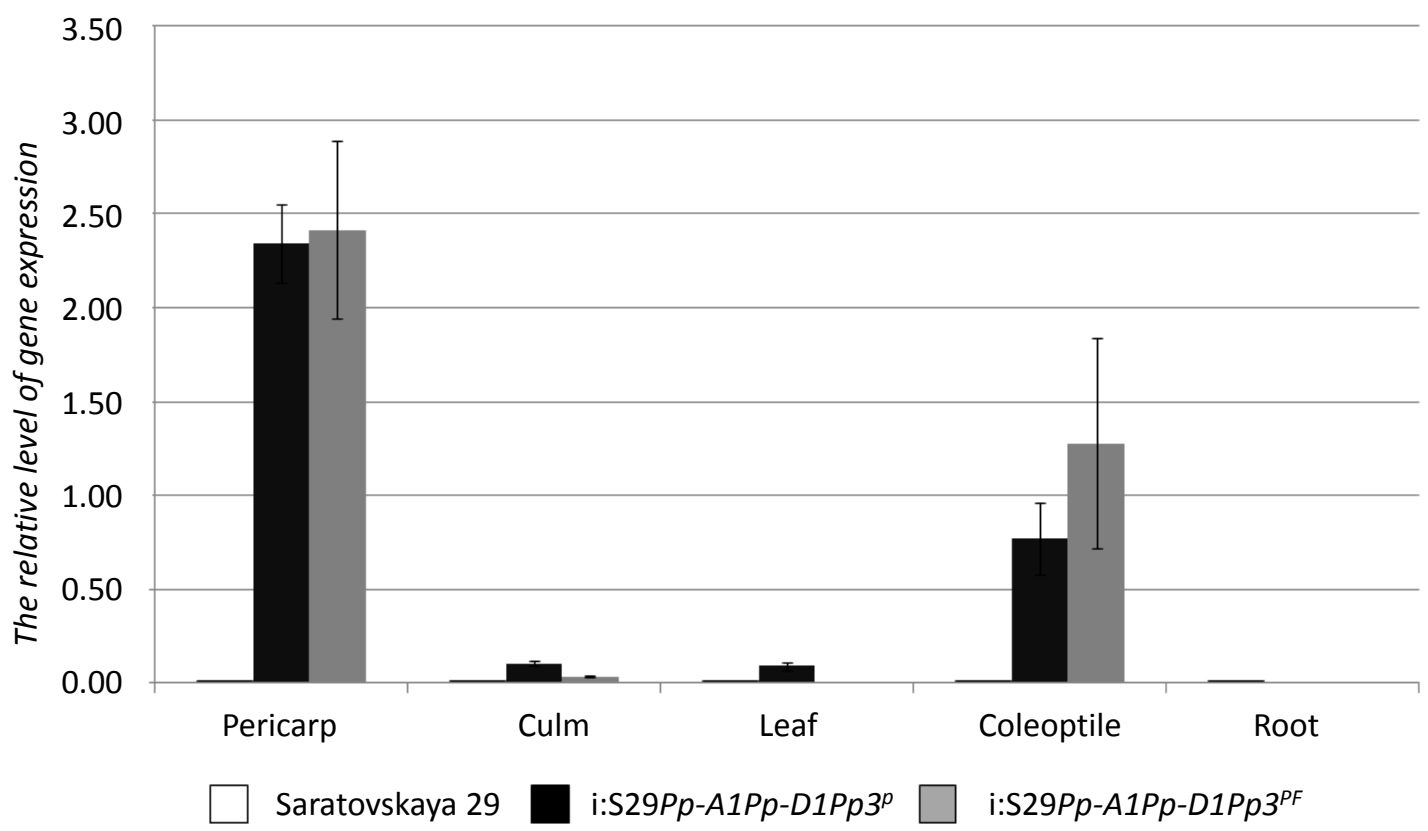




\subsection{The Full-Length Sequence of TaMyc1}

Sets of overlapping amplicons were generated to obtain the full sequence of the TaMycl copy present

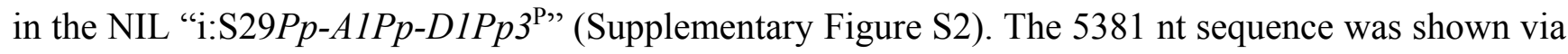
a comparison of the gDNA and cDNA sequences to be split into nine exons (Figure 5a). The first intron lay in the $5^{\prime}$ untranslated region as was determined by 5'RACE method. The length of the open reading frame was $1707 \mathrm{nt}$, and the predicted product was a 568 residue protein (Figure 5b) harboring a conserved basic helix-loop-helix (bHLH) domain encoded by exons 7 and 8 (Figure 5c).

Figure 5. (a) Gene structure of TaMyc1; (b) mRNA identified in the pericarp of the NIL "i:S29Pp-A1Pp-D1Pp3 $3^{\mathrm{P}}$; (c) The conserved bHLH domain. The translation start site (ATG) and stop codon (TGA). Black asterisks: amino acid contacts with nucleotide bases, small gray asterisks: amino acid contacts with DNA backbone, dots: non-polar residues important for protein-protein interactions.

a)

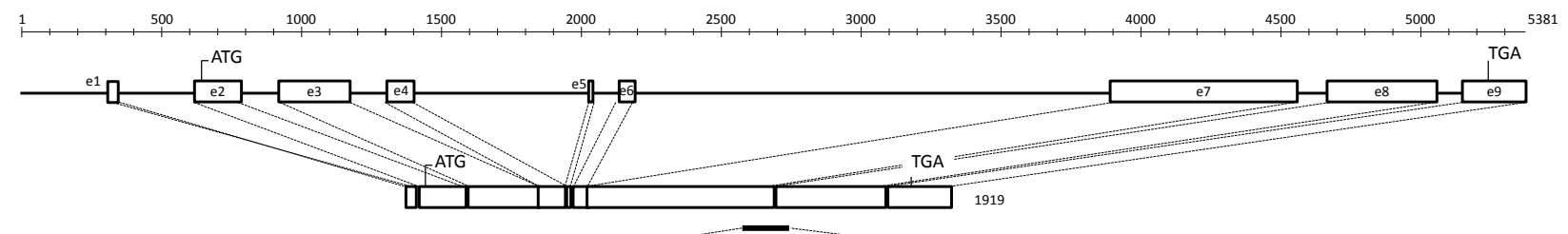

b)

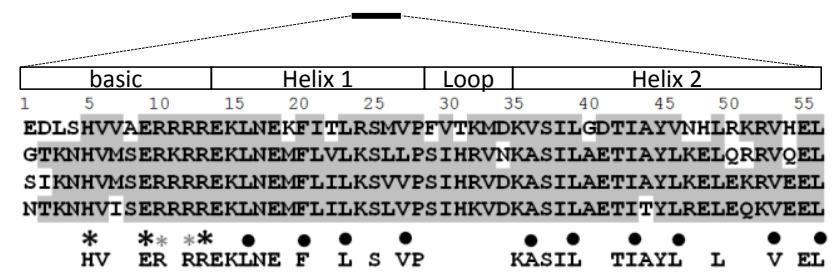

The bHLH domain consisted of 56 residues, split into a 13 residue segment dominated by basic amino acids and a longer segment predicted to form two amphipathic $\alpha$ helices separated by a 6 residue loop. The basic region contained the conserved residues $\mathrm{H}^{5}-\mathrm{E}^{9}-\mathrm{R}^{13}$, thought to be critical for DNA binding [35]. The highly conserved hydrophobic residues in helix 1 and 2 are believed to be necessary for achieving the dimerization of a pair of bHLH proteins [35]. An alignment of MYC-like proteins participating in anthocyanin synthesis revealed that they all (including that encoded by the TaMycl gene) shared, in addition to their bHLH domain, a highly conserved run of 200 residues at their $\mathrm{N}$ terminal end (Supplementary Figure S5). This segment has been implicated as being important for the proteins' interaction with R2R3-MYB TFs [36]. The structure of TaMyc1, the position of its bHLH domain and the presence of certain other conserved regions are all consistent with its involvement in the regulation of anthocyanin synthesis [35,37].

\subsection{TaMyc1 Transcription as Affected by the Combination of Pp Alleles Present}

Genotypes carrying dominant $P p 3$ (lines 1, 2, Figure 6) were associated with the most abundant TaMycl transcript, consistent with the notion that TaMycl is synonymous with Pp3. In genotypes harboring the dominant allele at $P p-D 1$, the abundance of TaMycl transcript was significantly lower than in those carrying the recessive allele (lines 1, 2, Figure 6). In lines with recessive allele at $P p 3$, dominant $P p-D 1$ also reduced the abundance of TaMycl transcript (lines 3, 4, Figure 6). The lowest 
level of TaMycl transcript was observed in the line bearing recessive alleles at $P p 3$ and both $P p-A 1$ and $P p-D 1$ (line 5, Figure 6). Described pattern of expression of the TaMyc1 gene was also observed for the complete lines set generated on cv. "Purple Feed" as a donor of the $P p$ genes (Supplementary Table S6). These data suggested that the presence of the dominant allele at $P p-D 1$ had an incomplete suppressive effect on the level of TaMycl transcription.

Figure 6. TaMycl transcription in the pericarp of NILs carrying various combinations of $P p$ alleles. 1: “i:S29Pp-A1pp-D1Pp3 ${ }^{\mathrm{P},}$ NIL, 2: “i:S29Pp-A1Pp-D1Pp3 $3^{\mathrm{P}}$, NIL, 3: cv. "Saratovskaya 29" (“i:S29Pp-A1pp-D1pp3”), 4: “i:S29Pp-A1Pp-D1pp3 $3^{\mathrm{P} "} \quad$ NIL, 5: "i:S29pp-A1pp-D1pp3" NIL. Statistical analysis of transcript abundances given in Supplementary Table S5. The phenotypes of lines set generated on "Purple" as a donor of $P p$ genes are shown.

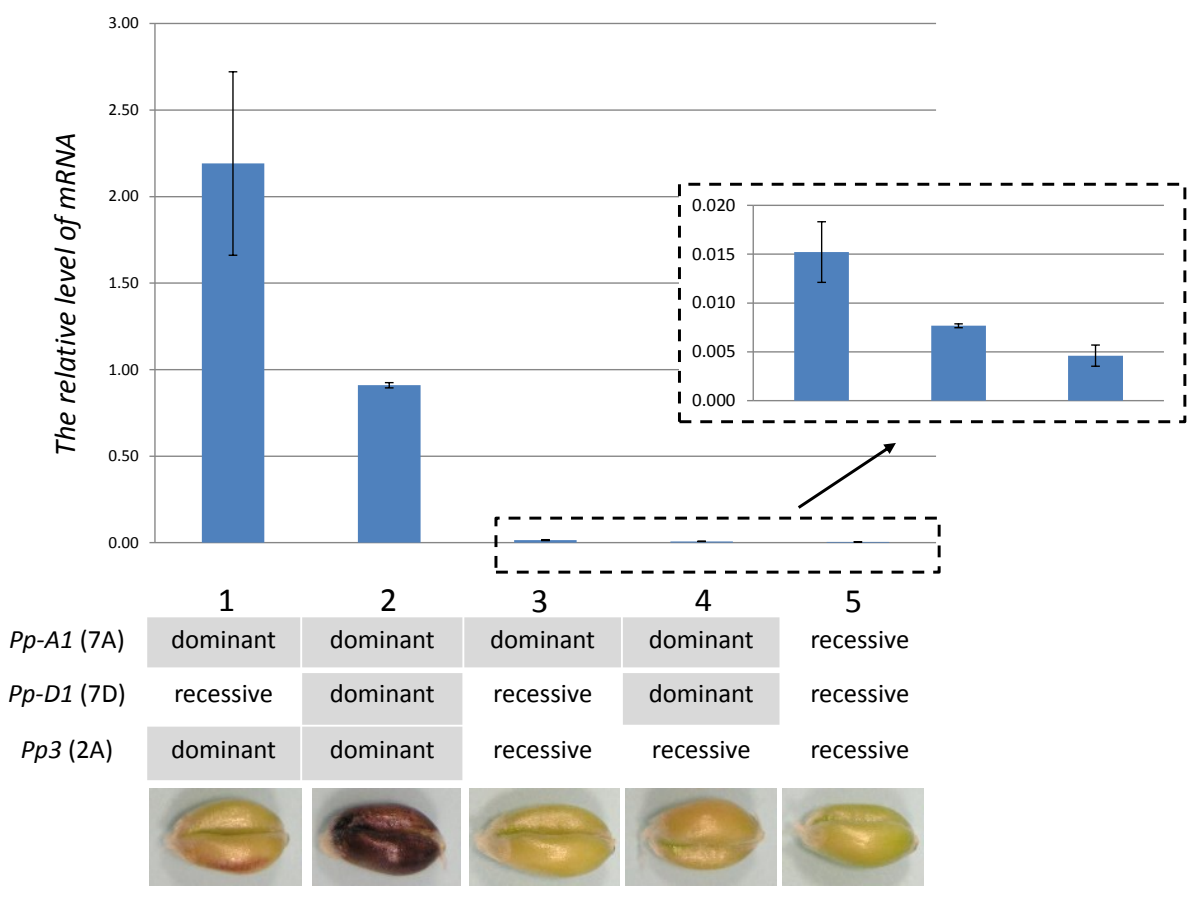

\section{Discussion}

The chromosomal location (Figure 2) and transcription profile (Figures 3 and 4) of TaMycl were all consistent with the notion that it is $P p 3$, one of the two complementary $P p$ genes required for the synthesis of anthocyanins in the pericarp. This gene has high level of structural similarity with the others genes (Figure 5, Supplementary Figure S5), that have been shown to encode bHLH transcriptional factors, participating in anthocyanin synthesis regulation, such as maize $L c$ and $B$, rice $R a$ and $P b$, Arabidopsis TT8, barley Ant2 [29-31,38-40]. Partial sequences of the other three Myc copies identified all shared a high level of sequence similarity with TaMyc1 (Figure 1, Supplementary Figure S3 and Table S3), but none of them was transcribed in the pericarp (Figure 3). Plant genomes typically harbor large numbers of bHLH-domain containing TFs, thought to have evolved via multiple duplication events followed by functional specialization $[29,41,42]$.

The TaMycl sequence is more similar to that of T. durum Mycl than it was to that of the A genome donor gene TuMyc. Assuming that TaMycl and TdMycl are orthologous, the implication is that TaMyc2 
and $T d M y c 2$ are their respective paralogs; the latter are directly related by descent to $T u M y c$. The purple grain trait has not been noted to date in any A genome diploid species [43]. As a result, it is likely that $T d M y c 1$ arose later than $T d M y c 2$ via a segmental duplication event post the formation of the BA tetraploid, and that TaMyc1 and TaMyc2 were transmitted from the BA tetraploid to the BAD hexaploid.

Although the functions of TaMyc2 through TaMyc4 have not been identified, it is possible that one or more of them do participate in anthocyanin synthesis, perhaps outside the pericarp, or in response to an external stimulus. In a number of plant species, anthocyanin synthesis is regulated by $\mathrm{TF}$ complexes $[44,45]$. The transgenic activation of the maize anthocyanin synthesis structural gene $\mathrm{Bz} 1$ requires the presence of both $C 1$ (an R2R3-MYB TF) and $B$ (a bHLH TF) [36]. Similarly, in Petunia hybrida, the TFs AN2 and PhJAF13 co-regulate a number of anthocyanin synthesis genes [37]. In wheat, anthocyanin synthesis in the culm, leaf and coleoptile is under the control of genes thought to be MYB family TFs [27]. TaMycl was up-regulated in the coleoptile (Figure 4), which implies that it may interact with the $M y b$ gene $R c$.

Anthocyanin biosynthesis in grain pericarp is controlled by two complementary $P p$ genes, which encode for R2R3-MYB and bHLH TFs. The pericarps of genotypes harboring the dominant allele at both $P p-1$ (R2R3-Myb) and Pp3 (Myc/bHLH) genes are pigmented from light to dark purple [25]. The presence of $P p-A 1$, inherited from cv. "Saratovskaya 29", in combination with $P p 3$, inherited from cvs "Purple" or "Purple Feed", ensures that the pericarp of each of the NILs "i:S29Pp-A1pp-D1Pp3" $3^{\mathrm{P} \text { " and }}$

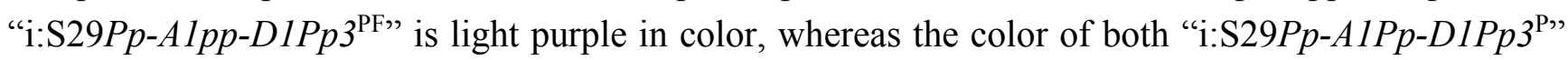

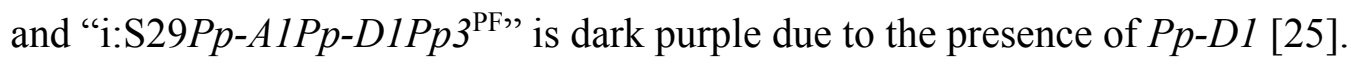

The transcription behavior of TaMycl varied according to the plant's $P p$ gene content (Figure 6). The highest abundance was noted in the combination $P p 3+P p-A 1$, although this feature was unrelated to the intensity of pericarp pigmentation, since the relevant NIL produced a light purple rather than a dark purple pericarp. The most intense pigmentation was seen in the combination $P p 3+P p-A 1+P p-D 1$, although in this case, the abundance of TaMycl transcript was only about half of that observed in the $P p 3+P p-A 1$ combination (Figure 6, Supplementary Tables S5 and S6). A similar interaction was noted where the recessive allele of $P p 3$ was present; in this case the overall levels of TaMyc1 transcript were much reduced (Figure 6, Supplementary Tables S5 and S6). The conclusion is that there is an influence exerted by the $P p-D 1$ genes on TaMycl expression, but the nature of the underlying mechanism is obscure. A possible model might involve negative feedback, in which the presence of an active R2R3-MYB/bHLH/WD40 (MBW) complex represses the transcription of TaMycl and leads to optimal proportion of partners in functional MBW complex.

Negative and positive feedback regulation of anthocyanin synthesis has also been reported in Arabidopsis thaliana [45]. Expression of the TT8 gene has been shown to be positively regulated by MBW complex including the WD40 TTG1, the MYBs TT2/PAP1 and the bHLHs TT8 itself or GL3/EGL3 [46]. In addition to this positive feedback regulation two negative regulators of anthocyanin synthesis were identified (MYBL2 and CPC), both of which encode single MYB repeat proteins [47,48]. Although both MYBL2 and CPC inhibit anthocyanin accumulation by repressing the biosynthesis genes [47,49], direct suppression of the $M y b$ and $b H L H$ regulatory genes expression has been also reported for MYBL2 [47]. 


\section{Experimental Section}

\subsection{Plant Materials}

$M y c$-like sequences were identified and isolated from the near-isogenic line (NIL) "i:S29Pp-A1Pp-D1Pp3 $3^{\mathrm{P} " ~(T a b l e ~ 1) ~ a n d ~ f r o m ~ T . ~ d u r u m ~ a c c e s s i o n ~ T R I 15744 ; ~ t h e ~ l a t t e r ~ w a s ~ o b t a i n e d ~}$ from the IPK genebank in Gatersleben (Germany). The chromosomal and intra-chromosomal locations of the wheat sequences obtained were assigned using nulli-tetrasomic, ditelosomic, and deletion lines of cv. "Chinese Spring" [50-52]. The other genetic stocks used to profile the transcription of the Myc genes are listed in Table 1.

\subsection{Gene Identification, Isolation and Sequence Analysis}

The maize $L c$ (GenBank accession M26227) and rice $R a$ (U39860) sequences were used as a query to identify a $M y c$-like sequence present on a $T$. urartu bacterial artificial chromosome (BAC) clone. A pair of PCR primers (pair 1: sequences given in Supplementary Table S2) was designed to amplify a segment of this gene, and was then used to recover its T. aestivum homologs via a PCR based on DNA extracted from fresh leaves following [53]. These and all subsequent primers were designed using OLIGO software [54]. Amplification of gDNA templates from the NIL "i:S29Pp-A1Pp-D1Pp3" was performed in $20 \mu \mathrm{L}$ PCRs each containing $1 \mathrm{U}$ Taq DNA polymerase (Medigen, Novosibirsk, Russia), $1 \times$ PCR buffer (Medigen), 1.5 or $1.8 \mathrm{mM} \mathrm{MgCl}_{2}$ (Supplementary Table S2), $0.2 \mathrm{mM}$ dNTP and $0.25 \mu \mathrm{M}$ of each primer. Amplification by different primer pairs was performed in distinct PCR conditions and amplification regimes (Supplementary Table S2). The amplified fragments were purified from a 1\% agarose gel, using a DNA Clean kit (Cytokine, St. Petersburg, Russia), then cloned using a PCR Cloning kit (Qiagen, Venlo, The Netherlands). Ten clones were sequenced in both directions to exclude any PCR and/or sequencing errors. The full length TaMycl sequence present in the NIL "i:S29Pp-A1Pp-D1Pp3" ${ }^{\mathrm{P}}$ " was re-constructed from a series of overlapping amplicons covering the relevant stretch of genomic DNA, using primer sequences designed from the sequences of contigs 249890, 467773, 1475001 and 1821237 (http://www.cerealsdb.uk.net) [55].

A Mint RACE primer set (Evrogen, Moscow, Russia) was used to obtain the ends of TaMycl transcripts present in the grain pericarp. Two rounds of $5^{\prime}$ and $3^{\prime}$ end amplification were conducted (primers listed in Supplementary Table S2). The resulting amplicons were cloned using a Qiagen PCR Cloning kit; a total of respectively, 35 and 12 clones obtained from the 5'- and 3'-RACE were sequenced in both directions. DNA sequencing was performed by SB RAS Genomics (Novosibirsk, Russia, http://sequest.niboch.nsc.ru). Multiple sequence alignments were carried out using Multalin v5.4.1 software [56], and the subsequent phylogenetic analysis using MEGA v5.1 software [57], based on the Neighbor-Joining algorithm and 1000 bootstrap replicates. Gene structure was determined using the FGENESH+ program [58] and confirmed by sequencing cDNAs obtained from the grain pericarp (Supplementary Table S2). 


\subsection{Chromosomal Assignment of Wheat Myc Sequences}

Amplification of gDNA templates from cv. "Chinese Spring" and its aneuploid derivates was performed in $20 \mu \mathrm{L}$ PCRs each containing $1 \mathrm{U}$ Taq DNA polymerase (Medigen, Novosibirsk, Russia), $1 \times$ PCR buffer (Medigen), 1.5 or $1.8 \mathrm{mM} \mathrm{MgCl}_{2}$ (Supplementary Table S2), $0.2 \mathrm{mM} \mathrm{dNTP}$ and $0.25 \mu \mathrm{M}$ of each primer. The amplification was initiated by a denaturing step $\left(94{ }^{\circ} \mathrm{C} / 2 \mathrm{~min}\right)$, followed by 13 cycles of $94{ }^{\circ} \mathrm{C} / 15 \mathrm{~s}, 65^{\circ} \mathrm{C} / 30 \mathrm{~s}$ (decreasing by $0.7{ }^{\circ} \mathrm{C} /$ cycle), $72{ }^{\circ} \mathrm{C} / 45 \mathrm{~s}, 24$ cycles of $94{ }^{\circ} \mathrm{C} / 15 \mathrm{~s}$, $56{ }^{\circ} \mathrm{C} / 30 \mathrm{~s}, 72{ }^{\circ} \mathrm{C} / 45 \mathrm{~s}$ and completed with a final extension step of $72{ }^{\circ} \mathrm{C} / 5 \mathrm{~min}$.

\subsection{Transcription Analysis}

A ZR Plant RNA MiniPrep ${ }^{\mathrm{TM}}$ kit (Zymo Research, Irvine, CA, USA) followed by DNAse treatment was employed to extract RNA from the grain pericarp, leaf, culm, coleoptile, and root of genotypes described in Table 1. Plants and seedlings for RNA extractions were grown, respectively, in greenhouse (ICG Greenhouse Core Facilities, Novosibirsk, Russia) or in climatic chamber "Rubarth Apparate" (RUMED GmbH, Laatzen, Germany) under $12 \mathrm{~h}$ of light per day at $20-25^{\circ} \mathrm{C}$. Pericarp samples for RNA extraction were peeled by scalpel from immature grains within 55th-75th day after sowing. RNA from leaf and culm were extracted within 70th-75th day after sowing. RNA samples from roots and coleoptiles were obtained on the fifth day after caryopsis germination. Single-stranded cDNA was synthesized in a $20 \mu \mathrm{L}$ reaction from a template consisting of $0.7 \mu \mathrm{g}$ total RNA using a (dT) 15 primer and a Fermentas RevertAid ${ }^{\mathrm{TM}}$ first strand cDNA synthesis kit (Fisher Scientific, Loughborough, UK). Subsequent RT-PCRs were primed either with $M y c$ copy-specific primers (Supplementary Table S2) or with the primers amplifying a segment of the genes $F 3 h, D f r$ and Ans [32]. A fragment of the wheat $U b c$ sequence (X56601) was used as the internal reference [59]. The PCR conditions and amplification regime were as above (Section 4.3), and the amplicons obtained were electrophoresed through $2 \%$ agarose gels. Quantitative RT-PCRs (qPCRs) were based on a SYBR Green I kit (Syntol, Moscow, Russia). Pre-determined quantities of cloned cDNA were used to generate a standard curve. Three biological replicates for each sample were run as three technical replicates. Differences in transcript abundance between lines were tested by applying the Mann-Whitney $U$-test [60], adopting a significance threshold of $p \leq 0.05$.

\section{Supplementary Materials}

Supplementary materials can be accessed at: http://www.mdpi.com/1420-3049/19/12/20266/s1.

\section{Acknowledgments}

We thank Galina Generalova for technical assistance, Robert Koebner (http://www.smartenglish.co.uk) for linguistic advice and valuable comments during the preparation of this manuscript, Valentina Arbuzova for near-isogenic lines, Andreas Börner for durum wheat seeds, and Marion Röder for DNA of wheat aneuploid stocks. This study was partially supported by RFBR (grant No 14-04-31637), grant from the President of the Russian Federation (MD-2615.2013.4), RAS (MCB Programme grant) and the State Budget Programme (Project No VI.53.1.5.). 


\section{Author Contributions}

Olesya Y. Shoeva and Elena I. Gordeeva performed the molecular genetic studies and analyzed the data, Olesya Y. Shoeva wrote the paper. Elena K. Khlestkina designed and coordinated the study, contributed to interpretation of data and to revising the manuscript critically. All authors read and approved the final manuscript.

\section{Conflicts of Interest}

The authors declare no conflict of interest.

\section{References}

1. Chalker-Scott, L. Environmental significance of anthocyanins in plant stress responses. Photochem. Photobiol. 1999, 70, 1-9.

2. Hatier, J.H.B.; Gould, K.S. Anthocyanin function in vegetative organs. In Anthocyanins: Biosynthesis, Functions, and Applications; Gould, K., Davies, K., Winefield, C., Eds.; Springer Science+Business Media: New York, NY, USA, 2009; pp. 1-19.

3. Wang, H.; Cao, G.; Prior, R.L. Oxygen radical absorbing capacity of anthocyanins. J. Agric. Food Chem. 1997, 45, 304-309.

4. Hale, K.L.; McGrath, S.P.; Lombi, E.; Stack, S.M.; Terry, N.; Pickering, I.J.; George, G.N.; Pilon-Smits, E.A. Molybdenum sequestration in Brassica species. A role for anthocyanins? Plant Physiol. 2001, 126, 1391-1402.

5. Hale, K.L.; Tufan, H.A.; Pickering, I.J.; George, G.N.; Terry, N.; Pilon, M.; Pilon-Smits, E.A.H. Anthocyanins facilitate tungsten accumulation in Brassica. Physiol. Plant. 2002, 116, 351-358.

6. Manetas, Y. Why some leaves are anthocyanic and why most anthocyanic leaves are red? Flora 2006, 201, 163-177.

7. Khlestkina, E.K. The adaptive role of flavonoids: Emphasis on cereals. Cereal Res. Commun. 2013, 41, 185-198.

8. Dell'Agli, M.; Busciala, A.; Bosisio, E. Vascular effects of wine polyphenols. Cardiovasc. Res. 2004, 63, 593-602.

9. Brown, J.E.; Kelly, M.F. Inhibition of lipid peroxidation by anthocyanins, anthocyanidins and their phenolic degradation products. Eur. J. Lipid Sci. Technol. 2007, 109, 66-71.

10. Wang, H.; Nair, M.G.; Strasburg, G.M.; Chang, Y.C.; Booren, A.M.; Gray, J.I.; DeWitt, D.L. Antioxidant and antiinflammatory activities of anthocyanins and their aglycon, cyanidin, from tart cherries. J. Nat. Prod. 1999, 62, 294-296.

11. Hui, C.; Bin, Y.; Xiaoping, Y.; Long, Y.; Chunye, C.; Mantian, M.; Wenhua, L. Anticancer activities of an anthocyanin-rich extract from black rice against breast cancer cells in vitro and in vivo. Nutr. Cancer 2010, 62, 1128-1136.

12. Tsuda, T.; Horio, F.; Uchida, K.; Aoki, H.; Osawa, T. Dietary cyanidin 3-O- $\beta$-D-glucoside-rich purple corn color prevents obesity and ameliorates hyperglycemia. J. Nutr. 2003, 133, 2125-2130.

13. Howard, B.V.; Kritchevsky, D. Phytochemicals and cardiovascular disease: A statement for healthcare professionals from the American heart association. Circulation 1997, 95, 2591-2593. 
14. Abdel-Aal, E.S.M.; Young, J.C.; Rabalski, I. Anthocyanin composition in black, blue, pink, purple, and red cereal grains. J. Agric. Food Chem. 2006, 54, 4696-4704.

15. Dykes, L.; Rooney, L.W. Phenolic compounds in cereal grains and their health benefits. Cereal Foods World 2006, 105-111.

16. Zofajova, A.; Psenakova, I.; Havrlentova, M.; Piliarova, M. Accumulation of total anthocyanins in wheat grain. Agriculture (Pol’nohospodárstvo) 2012, 58, 50-56.

17. Ficco, D.B.M.; de simone, V.; Nigro, V.F.; Finocchiaro, F.; Papa, R.; de vita, P. Genetic variability in anthocyanin composition and nutritional properties of blue, purple and red bread (Triticum aestivum L.) and durum (Triticum turgidum L. spp. turgidum var. durum) wheats. J. Agric. Food Chem. 2014, doi:10.1021/jf5003683.

18. Li, W; Pickard, M.D.; Trust, B. Effect of thermal processing on antioxidant properties of purple wheat bran. Food Chem. 2008, 104, 1080-1086.

19. Hirawan, R.; Diehl-Jones, W.; Trust, B. Comparative evaluation of the antioxidant potential of infant cereals produced from purple wheat and red rice grains and LC-MS analysis of their anthocyanins. J. Agric. Food Chem. 2011, 59, 12330-12341.

20. Zeven, A.C. Wheats with purple and blue grains: A review. Euphytica 1991, 56, 243-258.

21. Arbuzova, V.S.; Maystrenko, O.I.; Popova, O.M. Development of near-isogenic lines of the common wheat cultivar "Saratovskaya 29". Cereal Res. Commun. 1998, 26, 39-46.

22. Dobrovolskaya, O.B.; Arbuzova, V.S.; Lohwasser, U.; Röder, M.S.; Börner, A. Microsatellite mapping of complementary genes for purple grain colour in bread wheat (Triticum aestivum L.). Euphytica 2006, 150, 355-364.

23. Khlestkina, E.K.; Röder, M.S.; Börner, A. Mapping genes controlling anthocyanin pigmentation on the glume and pericarp in tetraploid wheat (Triticum durum L.). Euphytica 2010, 171, 65-69.

24. Tereshchenko, O.Y.; Gordeeva, E.I.; Arbuzova, V.S.; Börner, A.; Khlestkina, E.K. The D genome carries a gene determining purple grain colour in wheat. Cereal Res. Commun. 2012, 40, 334-341.

25. Gordeeva, E.I.; Shoeva, O.Y.; Khlestkina, E.K. Marker-assisted development of bread wheat near-isogenic lines carrying various combinations of $P p$ (purple pericarp) alleles. Euphytica 2015, in press.

26. Saitoh, K.; Onishi, K.; Mikami, I.; Thidar, K.; Sano, Y. Allelic diversification at the C1 (OsC1) locus of wild and cultivated rice: Nucleotide changes associated with phenotypes. Genetics 2004, $168,997-1007$.

27. Khlestkina, E.K. Genes determining coloration of different organs in wheat. Russ. J. Genet. Appl. Res. 2013, 3, 54-65.

28. Li, W.L.; Faris, J.D.; Chittoor, J.M.; Leach, J.E.; Hulbert, S.H.; Liu, D.J.; Chen, P.D.; Gill, B.S. Genomic mapping of defense response genes in wheat. Theor. Appl. Genet. 1999, 98, 226-233.

29. Hu, J.; Anderson, B.; Wessler, R. Isolation and characterization of rice $R$ genes: Evidence for distinct evolutionary paths in rice and maize. Genetics 1996, 142, 1021-1031.

30. Wang, C.; Shu, Q. Fine mapping and candidate gene analysis of purple pericarp gene $P b$ in rice (Oryza sativa L.). Chin. Sci. Bull. 2007, 52, 3097-3104. 
31. Ludwig, S.R.; Habera, L.F.; Dellaporta, S.L.; Wessler, S.R. $L c$, a member of the maize $R$ gene family responsible for tissue-specific anthocyanin production, encodes a protein similar to transcription activators and contains the myc-homology region. Proc. Natl. Acad. Sci. USA 1989, 86, 7092-7096.

32. Tereshchenko, O.Y.; Arbuzova, V.S.; Khlestkina, E.K. Allelic state of the genes conferring purple pigmentation in different wheat organs predetermines transcriptional activity of the anthocyanin biosynthesis structural genes. J. Cereal Sci. 2013, 57, 10-13.

33. Khlestkina, E.K.; Röder, M.S.; Pshenichnikova, T.A.; Börner, A. Functional diversity at the Rc (red coleoptile) gene in bread wheat. Mol. Breed. 2010, 25, 125-132.

34. Khlestkina, E.K.; Pshenichnikova, T.A.; Röder, M.S.; Börner, A. Clustering anthocyanin pigmentation genes in wheat group 7 chromosomes. Cereal Res. Commun. 2009, 37, 391-398.

35. Heim, M.A.; Jakoby, M.; Werber, M.; Martin, C.; Weisshaar, B.; Bailey, P.C. The basic Helix-Loop-Helix transcription factor family in plants: A genome-wide study of protein structure and functional diversity. Mol. Biol. Evol. 2003, 20, 735-747.

36. Goff, S.A.; Cone, K.C.; Chandler, V.L. Functional analysis of the transcriptional activator encoded by the maize $B$ gene: Evidence for a direct functional of regulatory proteins. Genes Dev. 1992, 6 , 864-875.

37. Quattrocchio, F.; Wing, J.F.; van der Woude, K.; Mol, J.N.M.; Koes, R. Analysis of bHLH and MYB domain proteins: Species specific regulatory differences are caused by divergent evolution of target anthocyanin genes. Plant J. 1998, 13, 475-488.

38. Cockram, J.; White, J.; Zuluaga, D.L.; Smith, D.; Comadran, J.; Macaulay, M.; Luo, Z.; Kearsey, M.J.; Werner, P.; Harrap, D.; et al. Genome-wide association mapping to candidate polymorphism resolution in the unsequenced barley genome. Proc. Natl. Acad. Sci. USA 2010, 107, 21611-21616.

39. Chandler, V.L.; Radicella, J.P.; Robbins, T.P.; Chen, J.; Turks, D. Two regulatory genes of the maize anthocyanin pathway are homologous: Isolation of $B$ utilizing $R$ genomic sequences. Plant Cell 1989, 1, 1175-1183.

40. Nesi, N.; Debeaujon, I.; Jond, C.; Pelletier, G.; Caboche, M.; Lepiniec, L. The TT8 gene encodes a basic helix-loop-helix domain protein required for expression of $D F R$ and $B A N$ genes in Arabidopsis siliques. Plant Cell 2000, 12, 1863-1878.

41. Ramsay, N.A.; Glover, B.J. MYB-bHLH-WD40 protein complex and the evolution of cellular diversity. Trends Plant Sci. 2005, 10, 63-70.

42. Feller, A.; Machemer, K.; Braun, E.L.; Grotewold, E. Evolutionary and comparative analysis of MYB and bHLH plant transcription factors. Plant J. 2011, 66, 94-116.

43. Tereshchenko, O.Y.; Pshenichnikova, T.A.; Salina, E.A.; Khlestkina, E.K. Development and molecular characterization of a novel wheat genotype having purple grain colour. Cereal Res. Commun. 2012, 40, 210-214.

44. Mol, J.; Grotewold, E.; Koes, R. How genes paint flowers and seeds. Trends Plant Sci. 1998, 3, 212-217.

45. Petroni, K.; Tonelli, C. Recent advances on the regulation of anthocyanin synthesis in reproductive organs. Plant Sci. 2011, 181, 219-229. 
46. Baudry, A.; Caboche, M.; Lepiniec, L. TT8 controls its own expression in a feedback regulation involving TTG1 and homologous MYB and bHLH factors, allowing a strong and cell-specific accumulation of flavonoids in Arabidopsis thaliana. Plant J. 2006, 46, 768-779.

47. Dubos, C.; le Gourrierec, J.; Baudry, A.; Lanet, E.; Debeaujon, I.; Routaboul, J.-M.; Alboresi, A.; Weisshaar, B.; Lepiniec, L. MYBL2 is a new regulator of flavonoid biosynthesis in Arabidopsis thaliana. Plant J. 2008, 55, 940-953.

48. Schellmann, S.; Schnittger, A.; Kirik, V.; Wada, T.; Okada, K.; Beermann. A; Thumfahrt, J.; Jürgens, G.; Hülskamp, M. TRIPTYCHON and CAPRICE mediate lateral inhibition during trichome and root hair patterning in Arabidopsis. EMBO J. 2002, 21, 5036-5046.

49. Zhu, H.F.; Fitzsimmons, K.; Khandelwal, A.; Kranz, R.G. CPC, a single-repeat R3 MYB, is a negative regulator of anthocyanin biosynthesis in Arabidopsis. Mol. Plant 2009, 2, 790-802.

50. Sears, E.R. Nullisomic analysis in common wheat. Am. Nat. 1953, 87, 245-252.

51. Sears, E.R. Isochromosomes and telocentrics in Triticum vulgare. Genetics 1946, 31, 229-230.

52. Endo, T.R.; Gill, B.S. The deletion stocks of common wheat. J. Hered. 1996, 87, 295-307.

53. Plaschke, J.; Ganal, M.W.; Roder, M.S. Detection of genetic diversity in closely related bread wheat using microsatellite markers. Theor. Appl. Genet. 1995, 91, 1001-1007.

54. Offerman, J.D.; Rychlik, W. Oligo primer analysis software. In Introduction to Bioinformatics: A Theoretical and Practical Approach; Krawetz, S.A., Womble, D.D., Eds.; Humana Press: New York, NY, USA, 2003; pp. 345-361.

55. Wilkinson, P.A.; Winfield, M.O.; Barker, G.L.A.; Allen, A.M.; Burridge, A.; Coghill, J.A.; Burridge, A.; Edwards, K.J. CerealsDB 2.0: An integrated resource for plant breeders and scientists. BMC Bioinform. 2012, 13, 219.

56. Corpet, F. Multiple sequence alignment with hierarchical clustering. Nucl. Acids Res. 1988, 16, 10881-10890.

57. Tamura, K.; Peterson, D.; Peterson. N.; Stecher, G.; Nei, M.; Kumar, S. MEGA5: Molecular evolutionary genetics analysis using maximum likelihood, evolutionary distance, and maximum parsimony methods. Mol. Biol. Evol. 2011, 28, 2731-2739.

58. Solovyev, V.; Kosarev, P.; Seledsov, I.; Vorobyev, D. Automatic annotation of eukaryotic genes, pseudogenes and promoters. Genome Biol. 2006, 7 (Suppl. 1), 10:1-10:12.

59. Himi, E.; Nisar, A.; Noda, K. Colour genes $(R$ and $R c)$ for grain and coleoptile upregulate flavonoid biosynthesis genes in wheat. Genome 2005, 48, 747-754.

60. Mann, H.B.; Whitney, D.R. On a test of whether one of two random variables is stochastically larger than the other. Ann. Math. Stat. 1947, 18, 50-60.

Sample Availability: Samples of DNA of near-isogenic lines are available from the authors.

(C) 2014 by the authors; licensee MDPI, Basel, Switzerland. This article is an open access article distributed under the terms and conditions of the Creative Commons Attribution license (http://creativecommons.org/licenses/by/4.0/). 